\title{
Consumer health information
}

\author{
Compiled by Susan Murray
}

\section{Top 10 Canadian consumer health Web sites}

The Consumer Health Information Providers Interest Group, an affiliate of the Canadian Health Libraries Association / Association des bibliothèques de la santé du Canada (CHLA / ABSC), is developing a top 10 Canadian consumer health Web sites list and hopes to present it at the annual CHLA / ABSC conference in May 2006. Committee members include Jean Williams, Elsie Petch, Elizabeth Puckering, Michelle Arbuckle, Kim Meighan, and myself. The top 10 Canadian consumer health Web sites list will be of value to consumers and health intermediaries as a good starting point for quality health information with a Canadian focus. Furthermore, it could also be used to publicize quality Canadian consumer health sites in the media. Lastly, we will be asking for your recommendations on CANMEDLIB and through other channels.

\section{Evidence-based herbal and dietary supplement information}

In December 2005, more than 100 herbal and dietary supplement monographs from Natural Standard, an evidence-based, peer-reviewed collection of information on alternative treatments, were added to MedlinePlus. Each herbal or supplement receives a grade ranging from " $\mathrm{A}$ " (strong scientific evidence for this use) to " $F$ " (strong scientific evidence against this use) for diseases or conditions it treats. In addition, each monograph provides information on dosing, safety, interactions, and selected references.

\section{Roundup of current readings}

Schwartz KL, Roe T, Northrup J, Meza J, Seifeldin R, Neale AV. Family medicine patients' use of the Internet for health information: a MetroNet study. J Am Board Fam Med. 2006;19:39-45. Available from http://www.jabfp. org/cgi/content/abstract/19/1/39?ct.

This study looked at a diverse sample of family medicine patients' use of the Internet for health information. It explored the extent of access to the Internet, types of health information sought, how the information was searched, and how patients assessed the accuracy of the information. It also surveyed the physicians' perceptions of their patients' use of the Internet for health information.
Griffiths KM, Christensen H. Website quality indicators for consumers. J Med Internet Res. 2005 Nov 15;7(5):e55. Available from http://www.jmir.org/2005/5/e55/.

This study aimed to determine (1) whether the instrument DISCERN is a valid indicator of evidence-based Web content quality for consumers without specific mental health training, and (2) whether Google PageRank is an indicator of Web site content quality as measured by an evidencebased gold standard.

Pew Internet \& American Life Project Report (released 28 December 2005). Available from http://www. pewinternet.org/pdfs/PIP_Women_and_Men_online.pdf.

Findings of this key report on Internet use in the US included the following statistics on accessing health information. Far more women $(74 \%)$ seek health or medical information online than men $(58 \%)$. The percentage of men and women who use the Web is nearly equal. Roughly $68 \%$ of men and $66 \%$ of women reported making use of the Web. When compared with Pew's 1995 study, this represents an increase of approximately $20 \%$, as in $1995,58 \%$ of the online audience were men.

Crumley ET. Exploring the roles of librarians and health care professionals involved with complementary and alternative medicine. J Med Libr Assoc. 2006 January;94(1):819. Available from http://www.pubmedcentral.nih.gov/ articlerender.fcgi ?artid $=1324776$.

The goals of this study were to identify resources health care professionals involved with complementary and alternative medicine (CAM) use, specifically, to explore the librarians' role as well as their approaches to teaching and searching with respect to CAM, to acquire information about CAM education, and to connect with other librarians in the CAM field.

Mays TL, editor. Consumer health issues, trends, and research: part 1: strategic strides toward a better future; part 2: applicable research in the 21 st century. Champaign, Ill.: University of Illinois Graduate School of Library and Information Science. Library Trends, 2004, Vol. 51, Nos. 2-3, ISSN 0024-2594.

A review, by Andrea Kenyon, of this special issue of Library Trends is in the Journal of the Medical Library Association, 
2006 January;94(1):91-2. I coauthored the following article in this special issue:

Kouame G, Harris M, Murray S. Consumer health information from both sides of the reference desk. Libr Trends. 2005;53(3):464-79.

Banick CR. RX for medical libraries. Libr J. 2005 Nov 15: 32-4. Available from http://www.libraryjournal.com/ article/CA6282616.html.

This article discusses the four main threats to small medical libraries: deprofessionalization, failure to do outreach, a shift in culture toward "McInformation", and ongoing budget crunches. (There was a brief exchange regarding "McInformation" on CANMEDLIB on January 20.)
Decooman D. Marketing library resources: an annotated bibliography. Elsevier Library Connect, pamphlet \#8, 2005. Available from http://www.elsevier.com/framework_ librarians/LibraryConnect/LCP08/LCP08.pdf.

Although most of us do not have sufficient time to market our services, not marketing is the kiss of death for libraries. This useful bibliography covers a range of libraries (academic and public), as well as different types of services (e.g., the article by Lillard discusses customer service for distance education students). 